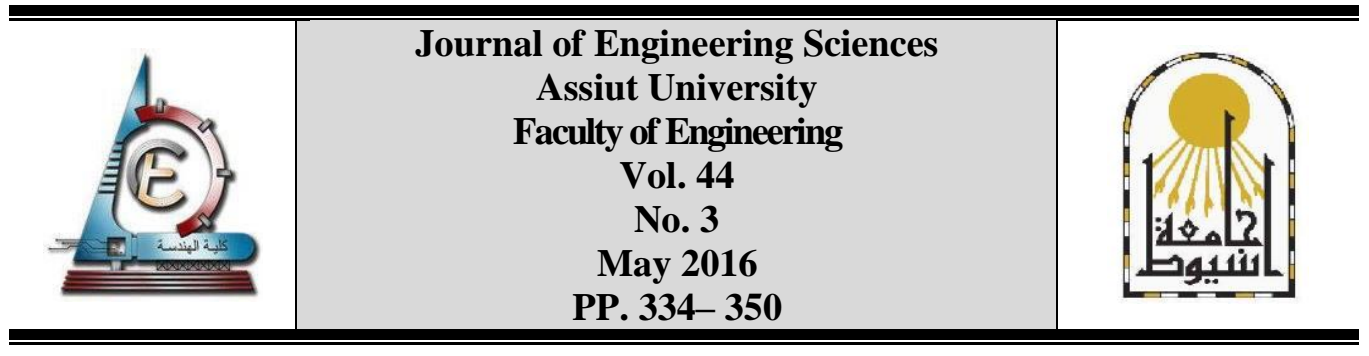

\title{
LINES EXPRESSION IMPACT IN PLANS CHARACTER IN DIFFERENT ARCHITECTURAL TRENDS
}

\author{
Mohamed Seif Elnasr \\ Department of Architectural - Faculty of Eng., Mattaria - Helwan University - Cairo - Egypt \\ Received 20 April 2016; Accepted 11 May 2016
}

\begin{abstract}
Buildings it is only an envelope for spaces serve various human activities, which need when exercised to a private spatial and environmental requirements and this space expressed by lines that form the components, as well as relations between the spaces and each other, and expresses these buildings two-dimensional lines in plans and facades and three-dimensional masses.

The study Supposed that the architectural lines in plans is the most important expressions about the architectural work character, whether in terms of architecture character, or the time of construction or construction materials or technology construction or architectural trends, and it can work an analytical model of for plans to know its shape character, causes and its intellectual thought through lines.

To get to achieve this hypothesis we will study the form characteristics of the architectural lines in terms of thickness, density and its geometric movement in space and its output in plans, also discuss the factors affecting these properties, such as building materials and structure systems and development time, and then applied to architectural schools in different eras to examine what distinguishes each school architectural other in expressing their plans, and formulate it in a guide model enables us to analyze any plans of yield expressionist lines and intellectual thought.
\end{abstract}

Key words: architectural lines - space organization- architectural expression- plans characterslines expressions - Architectural Trend.

\section{Introduction}

The design is a mental organization through handling multiple types of information and their integration into a single set of ideas, and ending with one of these ideas expressed through graphics process.

Shapes arises and determines its visual nature by formatting lines and controlling of its movements and trends, so that the lines express the structure skeleton of the design, whether in plans, elevations or masses, also express at the different architectural schools .

There is a strong relationship between form and line whereas the lines are the basis to separate the form with its virtual outlines from surrounding aspects. 


\subsection{The problem}

lines always are the expression tool of the architecture product historically or ideologically, recently there have been many of architectural ideas and schools, and because of plentiful has become the differences between them is simple and distinction between them are difficult so the need to a mechanism for distinguish between these ideas has appeared, and the most important elements of difference between them is the architectural lines constituents.

\subsection{Hypothesis}

Supposed to search the architectural lines in plans are the most important expressions of personal architectural work, whether in terms of architectural character, the time of construction, construction materials or construction technology or architectural trends, and it can be made an analytical model for plans to know the characteristics form, causes and ideological relationship through lines expressive architecture lines.

Architectural lines are an evidence that leads the eye to the center of attention and in the process of drafting the forms and providing them with movement energy, like when we see curved lines with incomplete lines, the eye complete the sense of these lines which making us think of continuity.

\subsection{Objectives}

1- Possibility of comparison between the buildings whether historically, ideologically or formulaically through architectural expression lines

2- Observe and identify the reflect of expressive lines in different architectural schools.

\section{1- Form elements:}

The main component element of the form is the line, and there is another elements complete sense of form such as texture, lighting, nature of constituent materials, so in this study we will take form as a variable element in lines and assume the stability of the other variables.

Lines used to express different things in the architectural design the most important is to transform information into spatial forms expressed through walls and elements above or below eye level, it is also used to express movement and stillness in plans, sensations of materials used and through the movement express levels and volumes.

\section{The purpose of lines in plans}

Buildings are only an envelope for spaces to serve various human activities, which need when exercised to especial spatial and environmental requirements. And lines express this space through its components, as well as relations between spaces.

We can define the purpose of the lines in plans as follows:

\subsection{Expression of architectural space components}

Architectural space forming of several elements, which are expressed by lines ${ }^{1}$ figure (1) as below:

* Architectural elements (floors-walls-ceilings).

* Structural elements (columns-ceilings-beams).

\footnotetext{
${ }^{1}$ Francis D.K.Ching : Interior Design Illustrated -van no strand Reinhold - new york 1987- p 11,16.
} 
* Spatial transition elements (windows-doors-pathes-stairs).

* Furnishing elements and technical systems.

\subsection{Spaces form relations}

The building usually contains several spaces that are connected to each other through the function or the movement paths, and they can be linked together in multiple basic ways $^{2}$, like as we see at figure (2).

\subsection{Sequence of space}

Circulation during the building consider as a visual line linking the interior and exterior spaces in building through the elements of the movement, whether outer one like approach or internal, such as entrances and paths of circulation in terms of form and its relationship with spaces in addition to the spaces distribution, it is worth mention that the paths are linear in nature and stems there form from the spaces that leading to them (linear-radiationspiral-gride-compact) ${ }^{3}$ as shown in Figure (3).

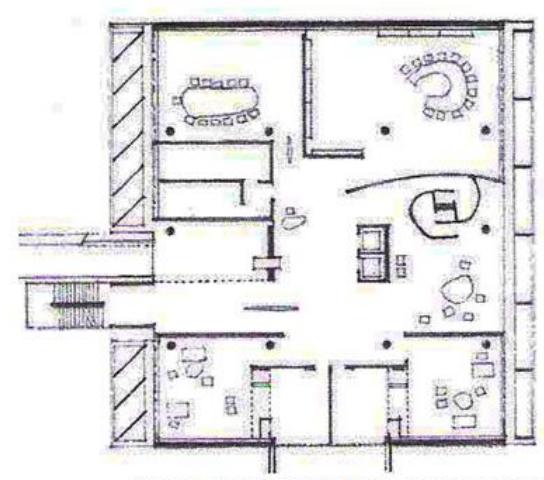

Fig. 1. Architectural space component Source: Architecture, form, space and order

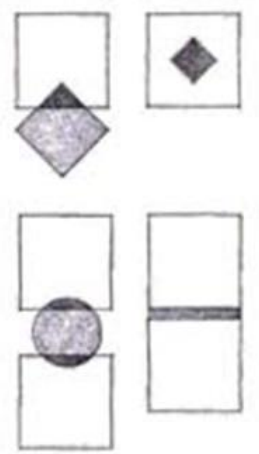

Fig. 2. Space form relationships Source: architecture, form, space and order

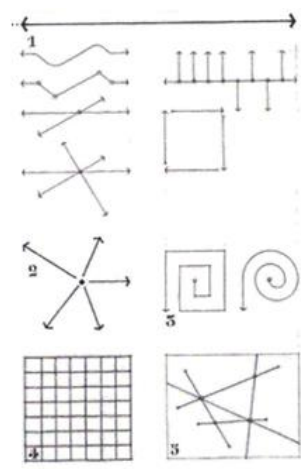

Fig. 3. Lines shapes Source: Architecture, form, space and order

\subsection{Expressing at space form}

the point is consider the creator to any forms, when the point move generated line and when the line moved in the direction opposite to the direction consists plane and at the plane move in perpendicular direction generate volume, The point, plane and volume are primary elements to form a shape, in other words, arise shapes and determines its visual nature by formatting lines and controlling of their movements and directions, so the lines form the structural Skelton of design.

The form indistinguishable from each other through the lines and planes that separate formation from its background or the surrounding space, the types and sources of the form is: figure (4).

* Natural forms: which have specific reference like symbols or anything that can be extracted from this symbol?

* Geometric forms: It is two basic types either a linear consisting of straight lines or curved forms which produced from a curved line

\footnotetext{
2 Francis D.K.Ching : Architecture Form, Space And Order - Second Edition - Library Of Congress - 1996- p185.

${ }^{3}$ Previous reference - p. 241 .
} 


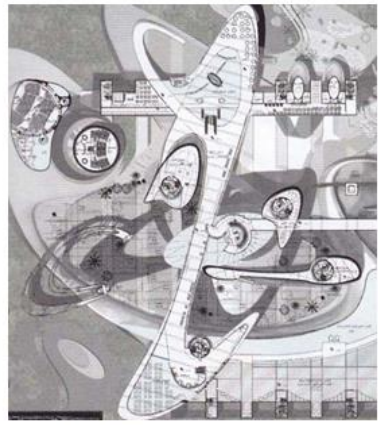

Symbolic forms

Science city -Egypt - Ahmed Meto

Source: Madina- issue 20

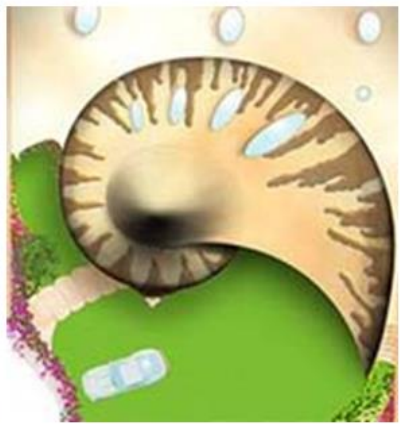

Natural abstract forms

Shell house - Mumbai, India

Source: www.tegaraworld.com

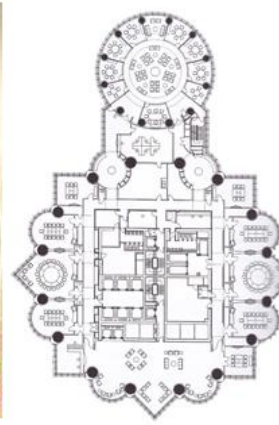

Geometric forms

Betronas tower-Malizia

Source: Madina- issue 12

\subsection{Expression of spatial organization ${ }^{4}$}

When assembly lines with specific repeat produces what is known as Module network which is the basis for form and organize the spaces between them and common link among all the requirements (functional program-outer determinants-formative requirements), and the types of these organizations as we see at figure (5).

\subsubsection{Centralized organization}

It consists of a central space surrounded by sub spaces even this spaces equal in shape or size or function blanks or not, these centralize may be radial, spiral or linear.

\subsubsection{Linear organization}

It is a continuous space intermittently connects the other spaces in a linear direction, which suggests motion, continuity and flexibility.

\subsubsection{Radial organization:}

It combines central and linear in terms of a control central space or central point and come out from it a linear regulation in radial way.

\subsubsection{Grid organization}

Module network is regular dimensions often result from structural or from standard architectural dimensions, and contain within it a different size, shape and function, spaces or a large space contain several spaces, and several networks can interfere together.

\subsubsection{Organic organization}

It's an organization result from using curved lines and makes flexible elastic spaces.

\subsubsection{Random organization}

Unorganized network from paths which connected together through specific points at the public space like service points or sub spaces.

\subsubsection{Clustered organization}

It is to incorporate spaces with each other via two or more of the above-mentioned organizations, and be a link between the various texture often through horizontal and vertical movement elements.

\footnotetext{
${ }^{4}$ Francis D.K.Ching : Architecture Form, Space And Order - Second Edition - Library Of Congress - 1996- p.195 .
} 


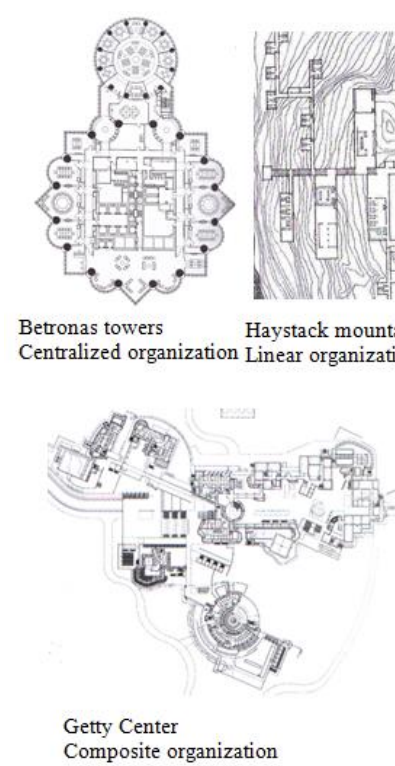

Fig. 5. Lines effect on spatial organization
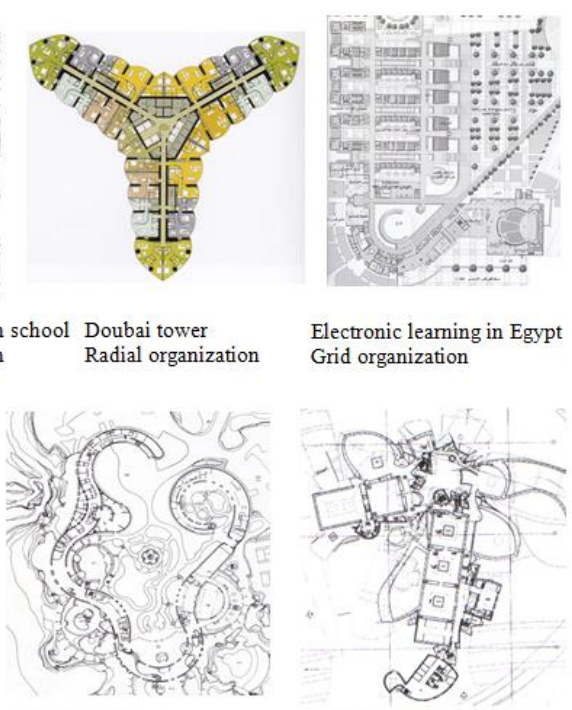

Tuwaiq palace Organic organization

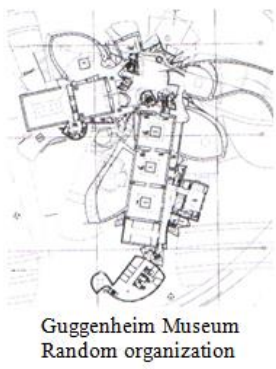

\section{Lines formation output in plans}

Lines formation output in plans differs from one era to another and from one thought to another, this dispute illustrated by:

\subsection{Thickness of lines}

Thickness of the lines in plans express at separation walls between the spaces and the line building material, whether structure or unstructured figure (6) in order to implement:

* Functional purpose: the meaning is the style of structure used and the type of construction material used, the diversity of expression from walls ranging from drilling in the mountains until the walls turned into partitions, light does not exceed a thickness of $5 \mathrm{~cm}$ moveable and adjustable space size, but has reached expression walls do not exist physically but appear and disappear through sensors with the viewer in art galleries, for example.

*Environmental purpose: Environmental treatment that are used in exterior walls to avoid noise, heat and external influences.

* Formation purpose: where the lines thickness is linked to the idea that the architect wants to be expressed and arrive to the recipient.

\subsection{Density of lines}

Expression density lines varied throughout history as a result of different building materials and technology construction, which has controlled the borders of spacing walls from each other, for example, in the Pharaonic stone buildings abounded pillars and size and convergence emerged lines expressing very thick and close walls, with the increasing of structural spans the less of lines and the intensity of the vertical support points, especially with the trend to universal space idea. 

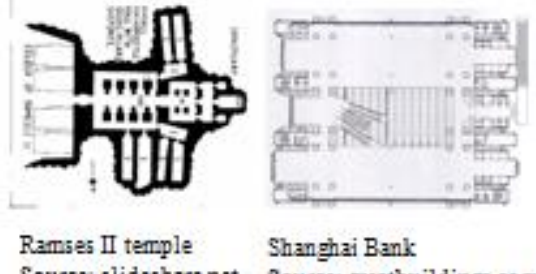

Source: slidesharenet Source: greatbuilding com

Functional purpose expression
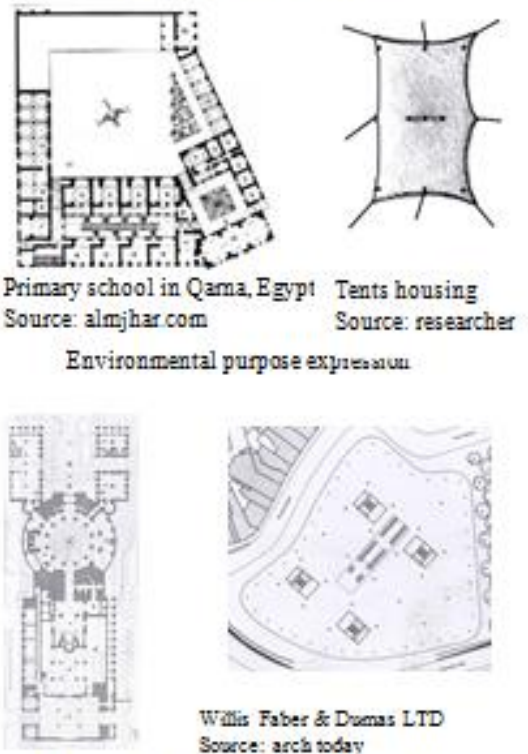

Wais Faber $\&$ Dremas LTD Sorces: arch today

Hyatt Regency hotel Source: arch today

Form purpose expression

Fig -5. Line thickness expression in plans

\subsection{The geometry of lines ${ }^{5}$}

lines form result from the point movement in space, and the study focus only at the twodimensional plans, lines movement system consider the basic expression tool of architectural idea, it is worth mentioning that these lines in formations that can be associated, but it must be controlled show and the superiority of the type one of them is the influence of other lines moderating and mitigating the boredom dominant type, the lines movement form and its psychological output figure (6) as follows.

\subsubsection{Straight line}

It's the main element of the formation emerges as the main influence for the formation from a repeat of the line, and the impression that the straight line is the strength, integrity and greatness and balance, whether horizontally or vertically so often we see it used in the relevant administrative, religious and medical projects, the types of this line are:

\footnotetext{
${ }^{5}$ Abdul-Aziz Nagaty: Shape and its relationship to the psychological situation of man, architecture for human, October 2013, p.1, 2, 3, 4.
} 
* Horizontal straight line: We cannot determine its direction unless it has been added elements able to guess the direction of movement.

* vertical straight line: suggests the direction from top to bottom, because the eyefollow weight direction in reading the line, and it making much less effort than that to read their upward movement of the lineup.

* Diagonal line: not achieve the sense of the public balance and stability of the building, which strongly affect the significance of trends and suggestions of movement.

\subsubsection{Refracted line}

Refracted line generate When the participation of several straight lines happened, which gives the impression of sharpness in the formation, for example, a refracted line consisting of two straight lines sets certain direction and whether the obtuse angle gives a sense of crush and diverge even the sharp angle gives a sense of strength rush either perpendicular angle gives the sense by balance.

\subsubsection{Curved line}

It gives a feeling of flexibility, freedom and dynamic, so we see these lines in the tourism and entertainment projects and examples of these lines is the spiral line.

\subsubsection{Random line}

It's an expression of instability and mind dispersion, this line used for special function and untraditional buildings like museums.

\subsubsection{Composite lines}

Is that involving the two or more of the previous lines together to form a composite sense of line?

\subsection{The third dimension of lines}

Free movement in the third dimension of the architectural composition the desired shape is responsible for the formation of plans according to the level of vision with clarity module network used in the design, which in turn allows for easy implementation, and with the use of the possibilities of computer software in the design of un traditional architectural forms and non-use of module network clear and exaggerated in the use of ripples separated appeared unread or expressive at functions and became the main reliance on the three dimensional model of the design, whether in design or implementation, and Frank Gary is consider one of the famous architects at this trend.

\subsection{Forming material of lines}

Lines expression in plans is affected depending on the used construction material and its properties, for example the stone that bears the pressure and does not bear tension So we find the expression in plans nearest and big diameters columns and and increased wall thickness as in Pharaonic temples, either concrete that bear both of pressure and tension so the expression become diverged and small columns also decreased the thickness of walls, and so on the other materials.

\section{The control factors at the lines formation evolution in plans}

\subsection{Construction material}

spaces are formed internally and divided by lines consisting of used construction material which were previously considered as a structural material like stone ,brick or 
wood, which was restricted the plans in terms of shape and size, but with the change of structure systems the walls become unstructured, but used to divide spaces and turned from heavy material to light materials such as gypsum board, glass, and did not become restrictive for spaces in terms of shape or size, and recently became the expression of the walls by the assumption, according to the movement of the user inside the space.

\subsection{Structure systems}

A long time ago man trying to deepen into the mysteries of material in general and structural materials, in particular, to learn about its properties and putting structure theories to make the best use of them, where the nature of the structural materials at the beginnings specify the architectural forms, where the use of natural materials such as stone, wood and clay, which imposed fixed forms and familiar was the main aim is avoiding tension stresses for inability of these materials on the tensile strength showed the small spans and hug and near pillars, with the technological development and the appearance of the dependable structure systems on manufactured materials like reinforced concrete, iron, plastics and glass structural that have the ability to resist stresses and the appearance of new structural possibilities for this manufactured materials that enable to make new architectural formations, large spans, small pillars and far between the structure sectors.

\subsection{Change in functional requirements}

Anciently, spaces Characterized by Privacy and smallest as a result of simple needs , privacy, building materials and structure available at this time.

with the change in the functional requirements that need to spaces larger appeared what is known as multi-use Spaces, and currently there is what is known as the virtual reality spaces and digital spaces, this means that the nature of space always change according to the developments taking place in all areas.

\subsection{The evolution of the expression of architectural lines tools techniques ${ }^{6}$}

As technology changed, the more ways of expressing lines at plans changed. After that was handy graphics have become automated and then became a three-dimensional model and then turned to a virtual reality... And so on...

The expression of architectural thought tools before the era of information technology are pen, paper, and the ideas of the designer, and his expression in sketches, and with the development of information technology appeared the industry programs, which interact with the architecture in two generations.

- First generation: - are helping to design programs such as CAD which doing the same process of drawing and traditional design, but it allowed the accuracy, speed and ease of modification and copying.

- Second generation:- the generation of digital models BIM, which help at design in an image of reality simulator model and stand on building performance and evaluation during the design process, therefore the drawing we need for design and implementation through this form graphics.

\footnotetext{
${ }^{6}$ Kymmell Willem: Building Information Modeling, NewYork, Mc Graw Hill. 2008, p.56.
} 


\subsection{Architectural thought}

Human vows in his outlook on the presence of one of two visions or thought, religion vision and physical vision, which is considered as the main framework for life and which are anything interpreted to exist accordingly.

The Ages concepts influenced by three main effects ${ }^{7}$;

1- Myth...Group of imaginable thoughts that settled down through the generations to finally be a wisdom become a power source "of legislation the group insured by it".

2- Religion ... a system of ideological and intellectual stemmed from God.

3- Ideology... a human intellectual production, which took the form located considerably since the beginning of the Renaissance and became the primary dominant since the eighteenth century.

These influences together that constitutes the concept of the ruling group and community, and the change in the priorities of ingredients does not necessarily mean a change in the concept, but it may mean a change "in the accompanying thought ... For example, the concept of religion was dominant for a long time but thought it changes from Pharaonic to Christianity to Islam, therefore religion is the concept but thought vary, and through the writings of critics Jencks, Kuhn, Collins and Baghdadi can division of eras with different concept into three main periods and within each era may contain many of the variables in the thought: -

\subsubsection{Pre Modernism architecture ${ }^{8}$}

it is mainly based on the full conviction of religion concept and there is always top model of measurement determines how successful of the ground model to approach and embodiment the model top, thus represented a realistic and simple world "slow change", and with variable of civilizations change the order of priorities that form ruling concept that I mentioned earlier" myth, religion, and philosophy, each civilization has its own character, which resulted in the construction of the existing material and structure systems are available.

\subsubsection{Architecture modernism ${ }^{9}$}

Physical vision become the main influential in the formation of global thought in the modern era since the Renaissance and became quite clear with the beginning of the eighteenth century, since humans cannot live without a form of measurement even he isn't a religion believer as a basis for the existence of the model, he is looking for it in science, nature, or philosophy and their applications are subject to measurement to determine their ability to achieve the model.

Modern architecture which form a mental picture of it a set of new multi-purpose buildings, in which geometric masses and pure structure of iron and glass cover of the building noticed with free of decorations and features, modern architecture contain three main directions and every direction has what distinguishes the plans as shown in Figure (7).

- function direction: - which means that the benefit is a prerequisite and that form follows function, and the expression in plans (the clarity of the structure from the outside - the complexity of interior and simplicity of exterior - transparent exterior walls - mechanical lines) Among the most famous architect of this direction Le Corbusier and his argument well-known that the house is a machine for living in.

\footnotetext{
7 Adly Mostafa:- Changing Ideals in Architecture, third scientific conference, azhar university, 1993, p.20 .

${ }_{9}^{8}$ previous reference, p.33

${ }^{9}$ Scully, v:- Modern Architecture" The Architecture of Democracy”, studio vista, London, 1968,p10 .
} 
- Organic direction:- It consider the building as a living organism grow from the inside to outside by forces that affect on the virtual form and interact with nature and is characterized by unity and lack of disintegration, and the expression in plans (use of appropriate construction materials to the environment - internal space compatibility with the outside - fit the external openings with the job - the interaction of external lines of plan with the surrounding environment).

- international style direction:- this trend based on the principle of simplicity in geometric shapes and get rid of everything that increase and the application of standardization, and the idea of plans based on the idea of universal space, a space can be divided as needed by partitions do not comply in distribution with the pillar points and do not affect the sense of the integration of the space as a single unit, the famous architect of this trend is Mies van der rohe with his famous words "less is more".
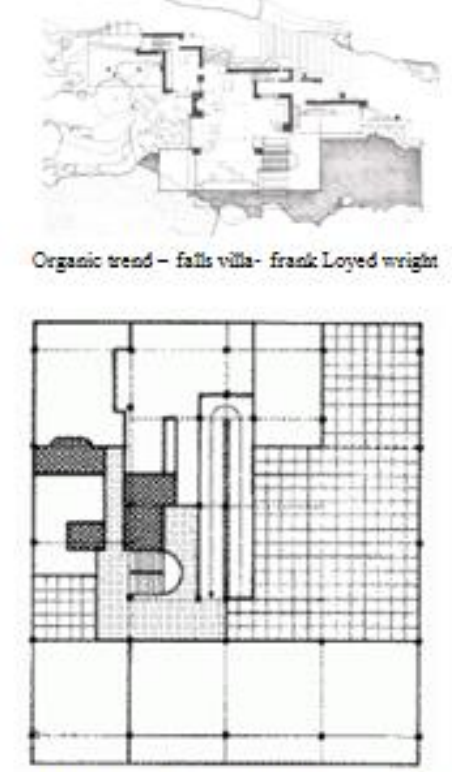

Functional trend-savoye villa-le corbusier

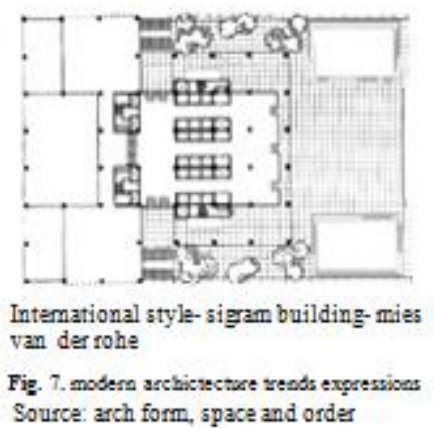

4.5.3. Contemporary architecture (pluralistic concept) ${ }^{10}$

Change is becoming the basic characteristic of this era in all fields, and It has called by Kuhn in his book "The Structure of Scientific Revolutions" "The Systematic World", theory of relativity to Einstein confirm that everything is relative between time and place,

${ }^{10}$ Zeilner Peter: - Hybrid Space’New Forms in Digital age”, London, thames \&Hudson, 1999. P.13 
and Newton's laws that emphasize continuity and agreed with the mechanical view of the world It is just only a very special case "of life and universe.

This new look affirmed that even science is uncertain, in quantum theory cannot reach the end of a physical certainty but everything discovers lead to something else, and therefore science itself is unlimited in one vision which led to extract mechanical view of society and the emergence of multi personal thought at all Areas of life ,

Contemporary architecture contains three trends which are:

\subsubsection{The Late Modernism architecture}

Late Modernism architecture is a practical direction characterized by exaggeration in the application of modern concepts such as full logical, the emphasis on movement axes, and focus on the mechanical aspects, the use of decorative technology and innovation, which is contrary to traditional architecture shapes with separation from history towards modernization and the establishment of self-contained building "no relation with the past", and this considered an advanced stage of the development of modern architecture.

Some of direction apply this thought are "high tech - neo expressionism - sculptural form - extreme articulation ".

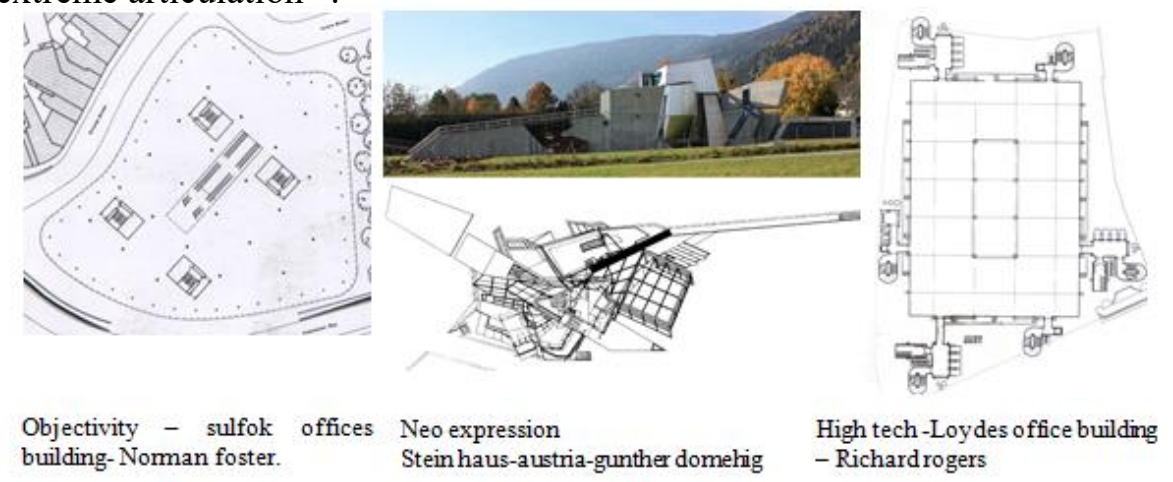

Fig. 8. Late modemism architecture

\subsubsection{The post modernism architecture}

Post modernism architecture appeared out of sync with the Late modernism architecture as it's going on the same concept with the continuous improvement of its ideology and principles, but they initiated reconsider its position towards the external shape, compatibility with the urban fabric, the observance of public taste and respect for tradition.

Trends that apply this thought (historical direction - revival direction - vernacular direction) figure (9).

\subsubsection{Digital architecture ${ }^{11}$}

Architecture passed in the era of information technology stages of development resembled developments that have affected the architecture in the era of the Industrial Revolution, from emergence of new types of buildings and ideas, theories reflect the urban life variants, where the faded border between fact and fiction and helped immaterial exchanges at direct communication and became the new innovations an output at Architecture and Urban, also digital technology helped on ease of forms production, thus opening the way for the architectural sculpture and forming spatial thought largest freely, there appeared what is known as the era of digital architecture, which raised important

${ }^{11}$ Rafat. Aly : future architecture, cairo,conselt research centre, 2007. 
question (Do form still follows function in the era of information technology?) the response was that form became follow the tool or technique.

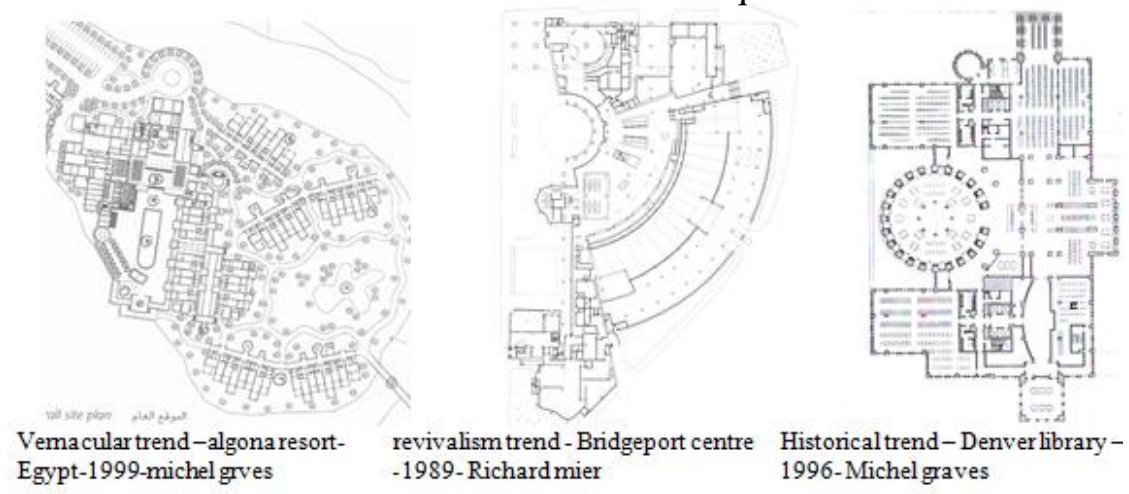

Fig. 9. Postmodem architecture

The IT era witness the turning of architectural design from traditional studio into a digital studio, and allowed to the architects new dimensions and theories during the design process by generation digital models BIM because of what made available from:

* Digital simulation of reality.

* Easy to generate ideas and formations

* Evaluation possibility of the ideas in the design phase

* The possibility of measuring building performance digitally

From many of the architects who have used and developed IT technologies we can divide digital architecture into three main trends as in the figure (10): -

* free sculptural architecture ${ }^{12}$ : which released from traditional forms and characterized by irregular in shape, spaces or surfaces which enabled the designer from getting out from Eukleides forms and creating what known as Topology shapes, and the most prominent architecture frank Gary.

* life architecture grow from the inside ${ }^{13}$ : which using the technology and the principles of smart architecture in achieving sustainability, saving energy and the perfect performance to the building with the surroundings environment, such as the works of Norman Foster, where we find plans with its traditional characteristics as The Late Modernism architecture.

* interactive moving architecture ${ }^{14}$ : unlike traditional and static architecture, that take advantage of technology in curriculum development and theories of design and interior function in which the building was technological interactive with its job, and the concept of the traditional space start to vanish and the emergence of what is known as hypothetical or hybrid space, and the architects of this trend spuybrock, lars and zaha hadid.

\section{Analytical Study}

From the previous theoretical study it can propose a guide model to express the formation of lines in different architectural schools, as in table (1), through which can

12 Kolarevic Branko : Architecture In The Digital Age . Design And Manufacturing, London, Taylor\&Francis , 2005 , p.103.

${ }^{13}$ Abel, Chris : Architecture, Technology And Process, Oxford, Architecture Press , 2004, p.95

${ }^{14}$ Spuybroek,Lart :Nox, London, Thames \& Hadson, 2004 , p.12. 
analyse any building plans, whether during the design or after implementation to determine the ideological trend, and this determination depending on stability of other variables such as three dimensional form and elevation details.

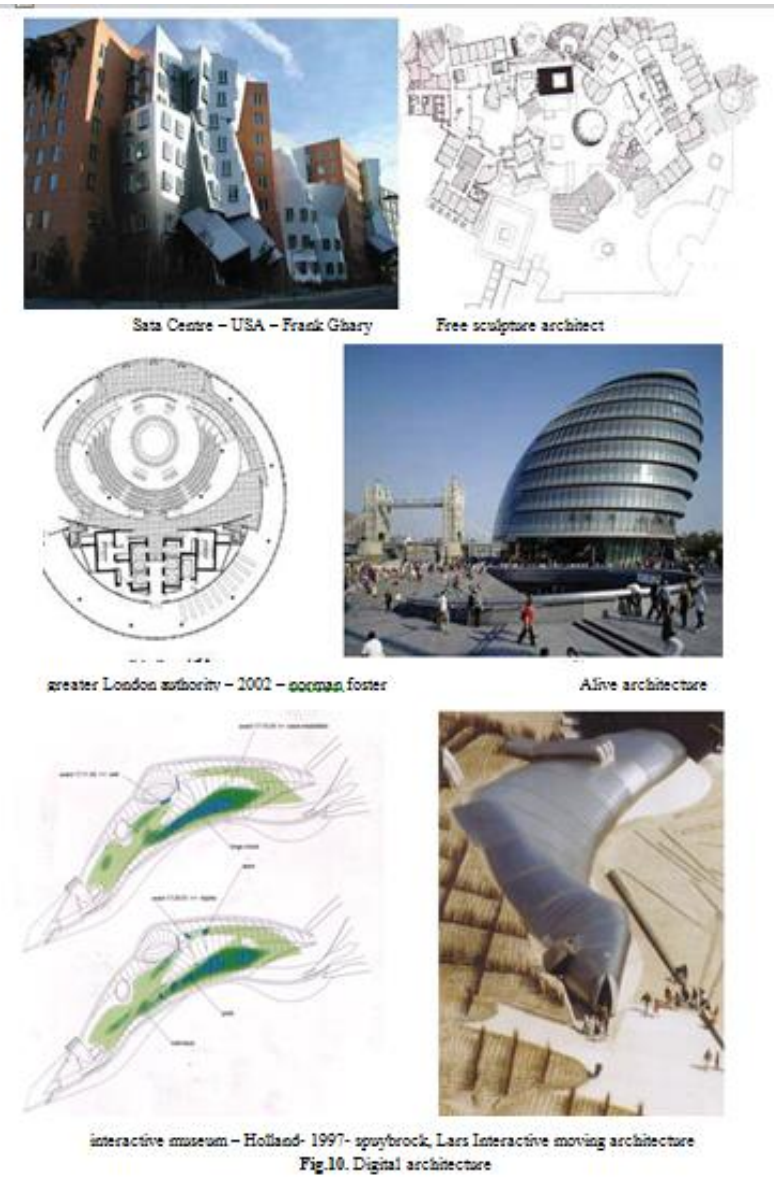

\section{Results and recommendations}

\subsection{Results}

1. Architectural lines are the most effective elements on plans character through several elements:

- Thickness of lines which define its purpose if a functional or environmental or form purpose.

- Density of lines where nearest or farest.

- Lines movement were straight, curved, composite or random.

- Influence at the space shape, whether natural or geometric.

2. Through the research have been made a reference model to monitor and determine the output of the expressive lines on plans in different architectural schools and thus historically, which can be used in monitoring and evaluation during the design process or determine the architectural trend of any exist building.

3. The conclusion of the reference model is that presence of some architectural trends are Like and complementary in the same form properties in plans, like revivalism in late modernism and function direction in modernism, also high tech in late modernism and 
international style in modernism, and free sculptural architecture in digital architecture is a continuation of neo expressionism in late modernism, and so on.
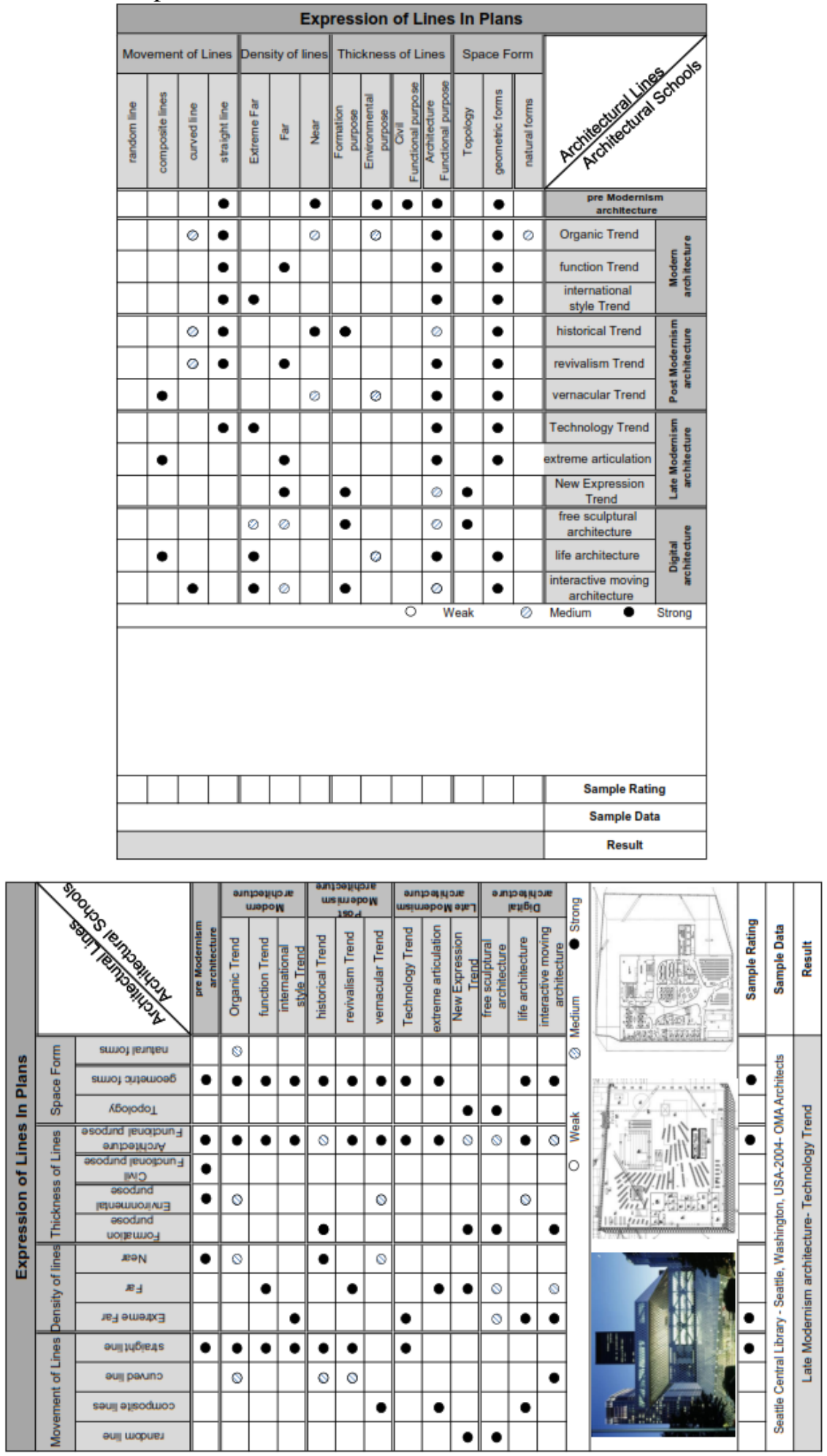


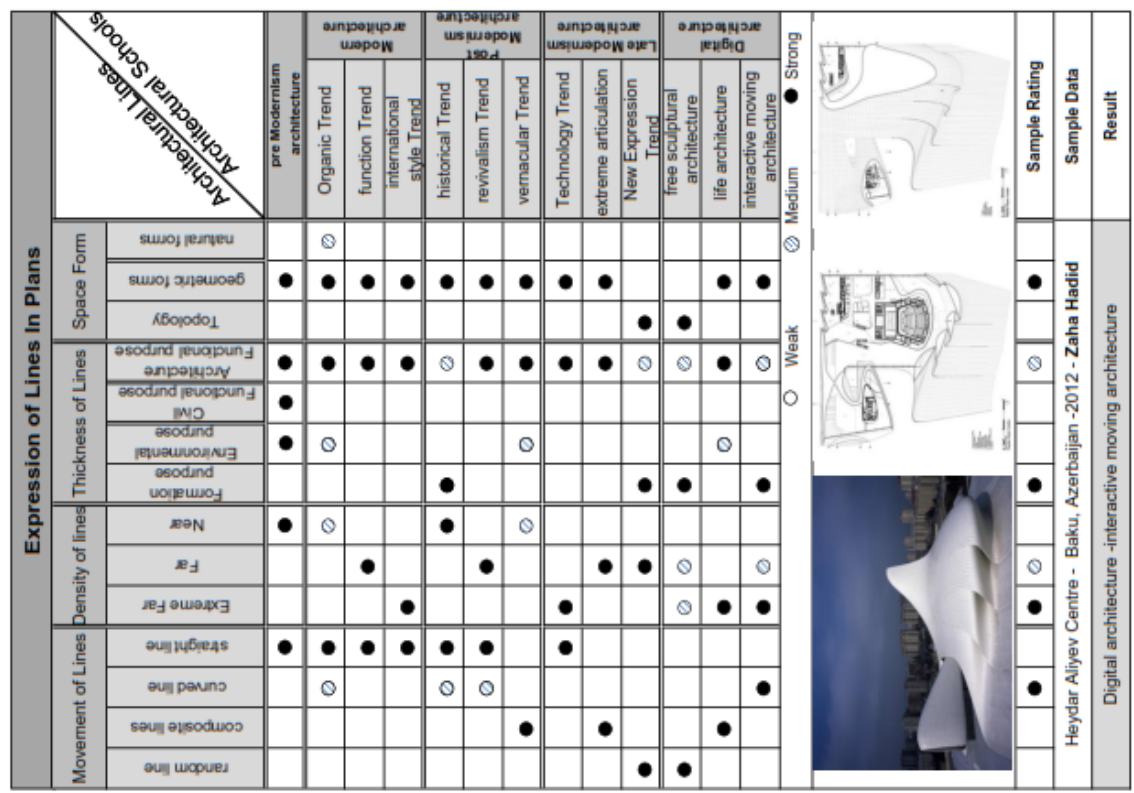

\subsection{Recommendation}

1- Continued research to develop the proposed reference model by increasing the study samples to gain access to more details of the expression elements in plans, and convert points of comparison to the more accurate numeric values can be generalized this form of measurement.

2- The need to monitor and document the expression of other points of personal architectural thought, which are three-dimensional form and elevation details in other measurement models and combined with plans model can even monitor and document the architecture of thought, whether during the design process or to the an exist building in all aspects.

3- Always follow-up the new in building materials and structure technology being one of the most important elements enriching the architectural thought.

4- The state must encourage the architects to use new materials and technology through provided it in the Egyptian market and encourage investors to use them by enacting laws that encourage it, such as customs cut and reduce the tax on the investor.

\section{REFERENCES}

[1] A.Jenks, Charles: The Language Of Post Modernism Architecture, London, Academy Edition, 1984.

[2] abdelaziz nagaty : Shape and its relationship to the psychological situation of man , architecture for human, October 2013.

[3] Abel, Chris: Architecture, Technology and Process, Oxford, Architecture Press, 2004.

[4] Francis D.K.Ching: Architecture Form, Space and Order - Second Edition - Library Of Congress -1996 .

[5] Francis D.K.Ching : Interior Design Illustrated -van nostrand reinhold - new york 1987.

[6] Giedion, S : Space, Time And Architecture , Cambridge ,Massachusetts Harvard, 1967.

[7] Kolarevic Branko: Architecture In The Digital Age. Design and Manufacturing, London, Taylor\&Francis, 2005.

[8] Kymmell Willem: - Building Informathon Modeling, NewYork, Mc Graw Hill. 2008. 
[9] Mohamed.nouby: architectural space from modernism to deconstruction, journal of engineering science, Assiut University, may 2007.

[10] Rafat. Aly: future architecture, cairo,conselt research centre, 2007.

[11] Spuybroek,Lart :Nox , London, Thames \& Hadson , 2004.

[12] Szalapaj, Peter: Cotemporary Architecture And The Digital Design Process. Oxford: Architectural Press, 2005.

[13]Zeilner Peter: - Hybrid Space”New Forms in Digital age”, London, thames\&Hudson, 1999.

[14]Zeynep Ceylanl :Sigfried Giedion"S "Space, Time And Architecture - An Analysis Of Modern Architectural Historiography - msc - Middle East Technical University - 2008 .

\section{Web sites}

1- http//: www.fosterand partners.com/projects/0793/default.aspx.

2- http//: www.nox-art-architecture.com/

3- http//: melbaz@ucas.edu.ps5.2015 


\section{أثر الخطوط في التعبيرعن شخصية المساقط الافقية في المدارس المعمارية المختلفة}

\section{الملخص العربى:}

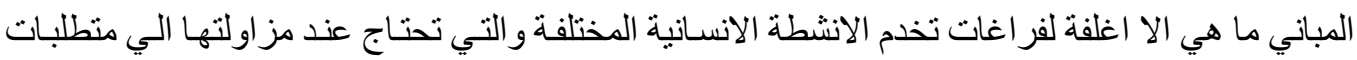

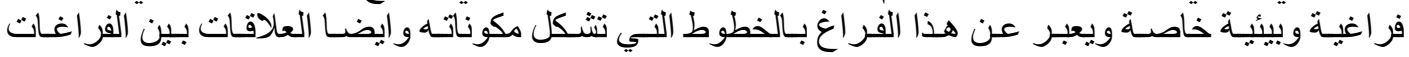
وبعضها البعض ، ويعبر عن هذه المباني بخطوط ثنائية الابعاد في المساقط و الواجهات وثنلاثية الابعاد في الكتل.

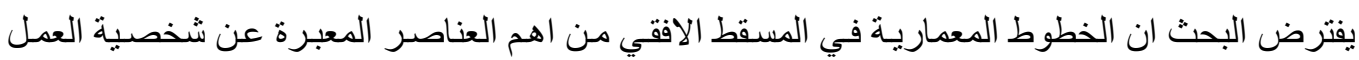

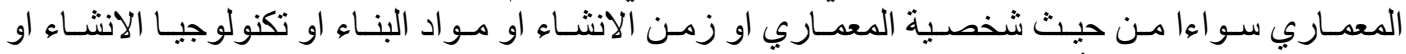

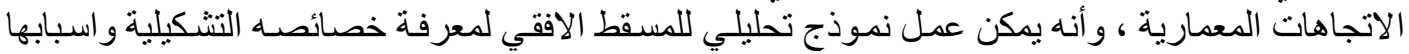
وانتماءاته الفكرية من خلاهل الخطوط ، وانه المكن المعبره عنه.

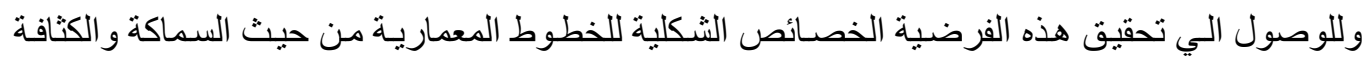

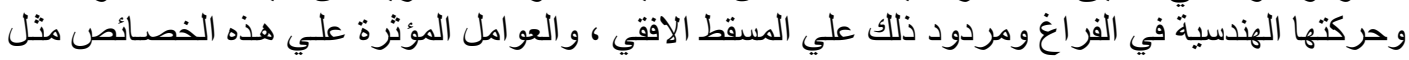

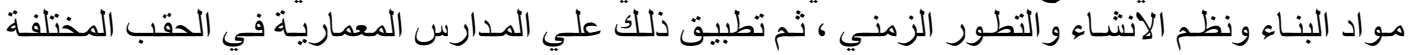

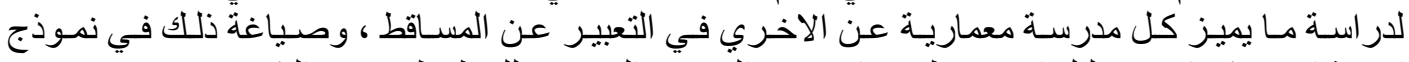

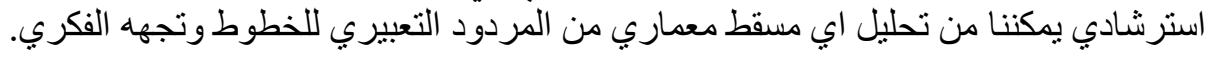

